\title{
Intra-Ventricular Tumors: Assessment of 40 Cases
}

\author{
Lütfi Ş. Postalcı1, Ömür Günaldı1 ${ }^{*}$, Bülent Demirgil1', Serhat Baydın1, Ender Ofluoğlu1, \\ Bekir Tuğcu1, Meral Günaldı ${ }^{2}$ \\ ${ }^{1}$ Bakirkoy Research and Training Hospital for Neurology, Neurosurgery and Phsychiatry, Neurosurgery Clinic, \\ İstanbul, Turkey \\ ${ }^{2}$ Bakirkoy Research and Training Hospital, Medical Oncology Clinic, Bakirkoy, İstanbul, Turkey \\ Email: omurgunaldi@gmail.com
}

Received 22 January 2014; revised 22 February 2014; accepted 1 March 2014

Copyright (C) 2014 by authors and Scientific Research Publishing Inc.

This work is licensed under the Creative Commons Attribution International License (CC BY).

http://creativecommons.org/licenses/by/4.0/

(c) (i) Open Access

\begin{abstract}
Objective: Intra-ventricular mass lesion has a significant position at diagnostic and therapeutic stage since they have deep localization and they are in close proximity with important neurovascular structures. We examined 40 patients who had surgical treatment for intraventricular mass lesion with respect to localization, symptoms, pathology, surgery method and outcomes. Method: 40 patients who were operated due to the ventricular mass lesion were examined with respect to the clinical picture and radiologic and pathologic findings as well as surgical methods and outcomes. Results: Of the mass lesions, 20 were located at lateral ventricle, 15 had $3^{\text {rd }}$ ventricle localization and 7 were located at $4^{\text {th }}$ ventricle. Ages of the patient ranged from 3 years to 67 years. The most common symptom was headache and nausea/vomiting. Interhemispheric trans-callosal approach was preferred for 19 patients, while transcortical approach and other methods were used for 12 patients and 9 patients, respectively. Conclusion: Considering the surgical methods and outcomes, the aim should be extraction of the mass lesion with minimum damage. Transcortical approach is more common for mass lesion located at lateral ventricle. Recently, endoscopic methods are more commonly and successfully used.
\end{abstract}

\section{Keywords}

Intraventricular, Tumor, Mass

\section{Introduction}

Intra-ventricular mass lesion has a significant position in the field of neurosurgery since they have deep loca"Corresponding author. 
lization and they are in close proximity with important cerebral structures. The recent technological advances and techniques significantly minimized the mortality and morbidity rates of tumors, which are located at this region, in comparison with previous rates [1] [2]. Intra-ventricular mass lesions are usually benign and the first line treatment is microsurgical resection [1] [3] [4]. The patient should be very carefully examined in the preoperative period and the best surgical method should be planned; the objective should be total extraction of the mass lesion with minimum neurological deficit [1] [2]. In the current study, we examined 40 patients who had surgical treatment for intraventricular mass lesion at our hospital between 2001 and 2011 with respect to localization, symptoms, pathology, surgery method and outcomes.

\section{Materials and Methods}

Totally, 40 patients who were operated due to the ventricular mass lesion at Neurosurgery Clinic of Bakırköy Research and Training Hospital for Neurology, Neurosurgery and Psychiatry were examined with respect to the clinical picture and radiologic and pathologic findings as well as surgical methods and outcomes.

Of the patients, 28 were male and 12 were female. Of the mass lesions, 20 were located at lateral ventricle, 15 had $3^{\text {rd }}$ ventricle localization and 7 were located at $4^{\text {th }}$ ventricle. Ages of the patients ranged from 3 years to 67 years. The most common symptom was headache and nausea/vomiting. Presentation complaints included epileptic seizure for 2 patients, vision disorder for 2 patients and dizziness for 6 patients. The distribution of baseline symptoms and findings by the localization is summarized in Table 1, Graphic 1, Graphic 2 and Graphic 3. The mean time between development of symptoms and application to the hospital is 0 - 60 month(s) (Mean: 15 months). At the presentation, GCS was below 15 only in 4 patients and GKS was equal to 15 in 36 patients.

Astrocytoma and glioblastoma were common in lateral ventricles, while colloid cyst was most frequently observed in the $3^{\text {rd }}$ ventricle and pylocytic astrocytoma was the most common clinical picture observed in the $4^{\text {th }}$ ventricle (Table 2). Astrocytic tumors and colloid cyst were more common for patients who were under 30, while the distribution was homogeneous over the age of 30 years (Table 3). According to the distribution between the pediatric age group and adult age group, whereas meningioma, central neurocytoma and choroid plexus papilloma were not seen in pediatric age group, choroid plexus carcinoma, ependimoma, pilocytic

Table 1. Distribution of presentation symptoms and findings by the localization of the mass.

\begin{tabular}{|c|c|c|c|c|}
\hline Symptoms & Lateral ventricle & 3. Ventricle & 4. Ventricle & Total \\
\hline Headache & 15 & 12 & 4 & 31 \\
\hline Nausea-vomiting & 8 & 11 & 2 & 21 \\
\hline Impaired consciousness & 4 & 2 & - & 6 \\
\hline Seizure & 1 & 1 & - & 2 \\
\hline Dizziness & 2 & 3 & 1 & 6 \\
\hline Motor deficit & 1 & - & - & 1 \\
\hline Speech disorder & 1 & - & - & 1 \\
\hline Impaired vision & - & 2 & - & 2 \\
\hline Impaired gait & - & - & - & - \\
\hline
\end{tabular}
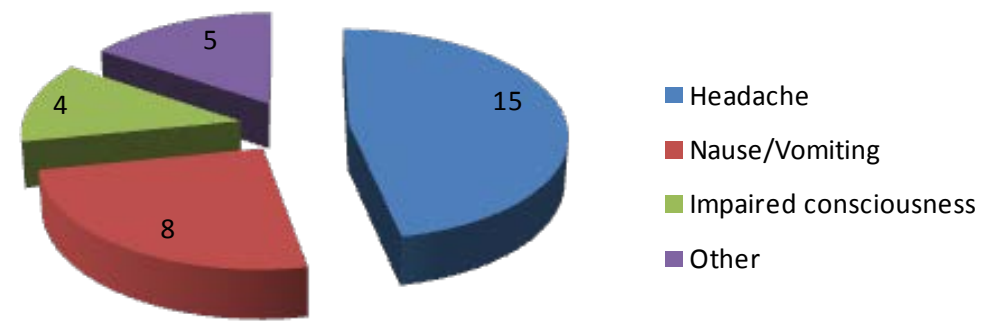

Graphic 1. Distribution of symptoms of lateral ventricle tumors. 


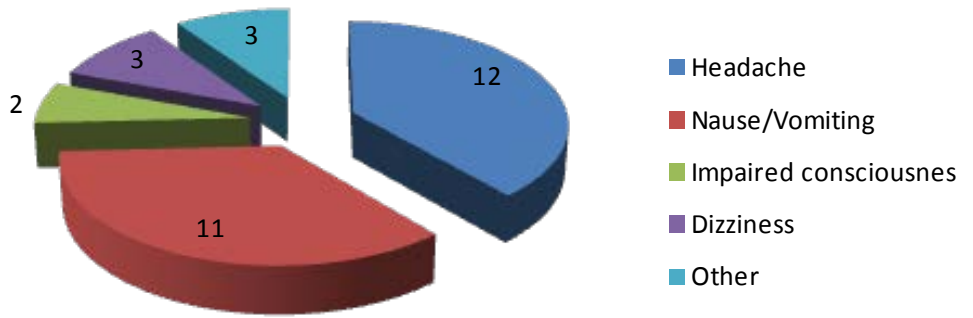

Graphic 2. Distribution of symptoms of third ventricle tumors.

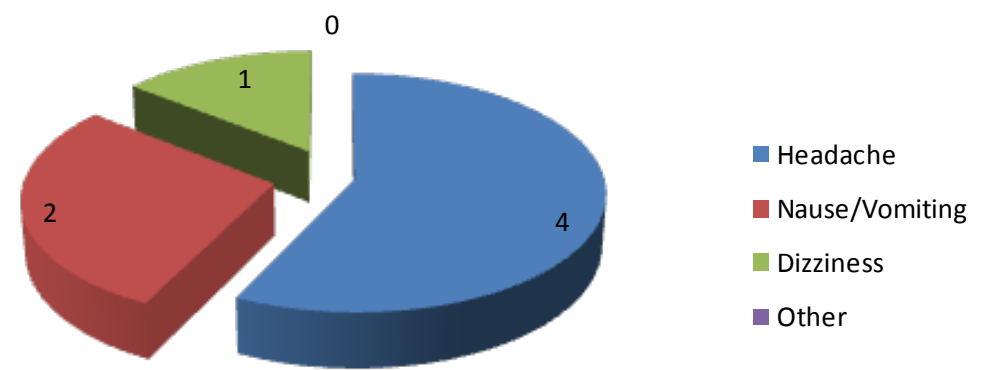

Graphic 3. Distribution of symptoms of fourth ventricle tumors.

Table 2. Distribution of pathological types by the localization of the mass.

\begin{tabular}{lccc}
\hline Pathological type & Lateral ventricle & 3. Ventricle & 4. Ventricle \\
Meningioma & 2 & - & - \\
Astrocytoma & 4 & 4 & - \\
Choroidal plexus CA & 1 & - & - \\
Central neurocytoma & 3 & - & - \\
Choroidal plexus papil. & 4 & - & - \\
GBM & 4 & 1 & - \\
Colloid cyst & - & 7 & - \\
Craniopharyngioma & - & 3 & 2 \\
Ependymoma & - & - & 2 \\
Pylocytic astrocytoma & - & - & 3 \\
Medulloblastoma & - & - & 7 \\
Total & 18 & 15 & \\
\hline
\end{tabular}

Table 3. Distribution of pathological types by the age range.

\begin{tabular}{|c|c|c|c|c|c|c|c|c|}
\hline Pathological type & $0-10$ & $11-20$ & $21-30$ & $31-40$ & $41-50$ & $51-60$ & $61-70$ & Total \\
\hline Meningioma & - & - & - & 1 & 1 & - & & 2 \\
\hline Astrocytoma & 1 & 3 & 2 & - & 1 & - & 1 & 8 \\
\hline Choroidal plexus CA & 1 & - & - & - & - & - & & 1 \\
\hline Central neurocytoma & - & - & 1 & 1 & 1 & - & & 3 \\
\hline Choroidal plexus papil. & - & - & 1 & - & 1 & 1 & 1 & 4 \\
\hline GBM & - & 1 & 1 & 1 & 2 & - & & 5 \\
\hline Colloid cyst & - & 1 & 1 & 4 & 1 & - & & 7 \\
\hline Craniopharyngioma & 1 & - & 1 & - & - & - & 1 & 3 \\
\hline Ependymoma & 1 & 1 & - & - & - & - & & 2 \\
\hline Pylocytic astrocytoma & - & 2 & - & - & - & - & & 2 \\
\hline Medulloblastoma & 2 & 1 & - & - & - & - & & 3 \\
\hline Total & 6 & 9 & 7 & 7 & 7 & 1 & 3 & 40 \\
\hline
\end{tabular}


astrocytoma and medulloblastoma were not seen in adult age group (Table 4). Interhemispheric trans-callosal approach was preferred for 19 patients, while transcortical approach and other methods were used for 12 patients and 9 patients, respectively (Table 5). Total resection was preferred in 40 patients, while stereotactic biopsy was performed for 2 patient and totally, 11 patients underwent subtotal resection including one patient who had stereotactic biopsy. In the postoperative period, 6 cases had hydrocephalus, 2 patients suffered intra-ventricular hemorrhage, while meningitis, subdural collection, CSF fistula, motor deficit and death secondary to the surgical complications developed in 5, 1, 1, 2 and 2 patients, respectively. Ventriculoperitoneal shunt was placed for patient who required (developed) hydrocephalus, while other complications were treated with conservative methods (Table 6). With respect to patient with follow-up data, it was found that 12 had died and histopathological types included GMB (4), Astrocytome (3), medulloblastoma (2), craniopharyngioma (1), choroid plexus carcinoma (1) and ependymoma (1).

Table 4. Distribution of hystopathological types between the pediatric age and adult age.

\begin{tabular}{lccc}
\hline Pathological type & Pediatric $(<\mathbf{1 8})$ & Adult $(\mathbf{1 8})$ & Total \\
\hline Meningioma & - & 2 & 2 \\
Astrocytoma & 4 & 4 & 8 \\
Choroidal plexus CA & 1 & - & 1 \\
Central neurocytoma & - & 3 & 3 \\
Choroidal plexus papil. & - & 4 & 4 \\
GBM & 1 & 4 & 5 \\
Colloid cyst & 1 & 6 & 7 \\
Craniopharyngioma & 1 & 2 & 3 \\
Ependymoma & 2 & - & 2 \\
Pylocytic astrocytoma & 2 & - & 2 \\
Medulloblastoma & 3 & - & 3 \\
Total & 15 & 25 & 40 \\
\hline
\end{tabular}

Table 5. Surgical approaches by the localization.

\begin{tabular}{lccc}
\hline Surgical approach & Lateral ventricle & 3. Ventricle & 4. Ventricle \\
\hline Interhemispheric trans-callosal & 6 & 13 & Total \\
Transcortical & 11 & - & 2 \\
Pteryonal & - & 2 & - \\
Suboccipital Infratentorial & - & - & 3 \\
Supravermian & - & - & 2 \\
Stereotaxis & 13 & - & - \\
Total & 18 & 15 & 7 \\
\hline
\end{tabular}

Table 6. Surgical complications observed for patients.

\begin{tabular}{ccc}
\hline Complication & Number & Conclusion \\
\hline Hydrpcephalus & 6 & V-P shunt, improvement \\
Ventricular hemorrhage & 4 & Conservative treatment, 1 death \\
Meningitis & 5 & Conservative treatment, improvement \\
Subdural collection & 1 & Conservative treatment, improvement \\
CSF fistula & 1 & Conservative treatment, improvement \\
Motor deficit & 2 & Conservative treatment, sequel \\
\hline
\end{tabular}




\section{Discussion}

Inteaventricular tumors accounts for $10 \%$ of CNS tumors [9]. Most of them are low-grade and slowly enlarging tumors. They usually occludes CSF circulation resulting with hydrocephalus and raised intracranial pressure syndrome. They reach high volume until findings of hydrocephalus emerge and they require usually emergency intervention [1] [5] [6].

Intraventricular tumors are commonly presented with symptoms of raised intracranial pressure syndrome such as headache, nausea and vomiting. Tumors may also associate with focal neurological findings secondary to the compression effect depending on the localization [6]. The rate of hemiparesis was reported as $7 \%-27 \%$, while the rate of epilepsy is 10 - 16 percent [5]. Our patient had baseline complaints secondary to the raised intracranial pressure syndrome including headache in $77 \%$ of patients and nausea/vomiting in 50 percent. The baseline complaint was epilepsy only for 2 of 40 patients (5\%) and intermittent headache and nausea/vomiting were identified on the medical history of those patients. The presentation complaint was hemiparesis for 1 patient (2.5\%). In addition, it was found that that patient had previous complaints secondary to the raised intracranial pressure. It was found that the rate of raised intra-cranial pressure-emerged complaints was consistent with that of the literature, but the rate of motor deficit and epileptic complaints was seriously below the rate reported in the literature. The lower rate may be related with the fact that the access to the healthcare facilities is easy in the city where our hospital is located, most patients had high sociocultural level and accordingly, almost all patient applied to the healthcare facilities without delay until the disease progresses.

There is no sexual difference for ventricular tumor based on the literature data [5]. However, our results indicated that $70 \%$ of patients were male subjects. Particular tumor types are more frequent at particular ventricular localizations. Therefore, the tumor localization, radiological appearance, symptoms and patient's age offer tips in estimating the pathological type of the tumor. Colloid cyst is more common in the $3^{\text {rd }}$ ventricle, followed by hypothalamic astrocytoma. For pediatric and adolescent population, low-grade gliomas are most commonly observed at lateral ventricles. Medulloblastoma and plylocytic astrocytoma are most commonly observed in the $4^{\text {th }}$ ventricle at pediatric-childhood age. Meningiomas are more common at $5^{\text {th }}$ decade and in lateral ventricles. Central neurocytoma is more common at $4^{\text {th }}$ decade and in lateral ventricles [5]-[8] [10] [11]. In the current study, localizations of tumors were almost completely consistent with the literature data with respect to the pathological diagnosis. Cases with meningioma were more common at $4^{\text {th }}$ and $5^{\text {th }}$ decades and only in lateral ventricles, while high-grade astrocytomes were observed almost in all age groups only at localization of lateral ventricle and $3^{\text {rd }}$ ventricle; central neurocytoma is frequent in the age range of 20 to 50 years only at localization of lateral ventricle and the choroid plexus papilloma is more commonly observed at ages above 25 years only at lateral ventricle; colloid cyst prefers $3^{\text {rd }}$ ventricle localization for adolescent and adult population; craniopharyngioma, ependymoma, pylocytic astrocytoma and medulloblastoma are all the diseases of first 2 decades and craniopharyngioma is more commonly found at $3^{\text {rd }}$ ventricle and others prefer the $4^{\text {th }}$ ventricle. The most malignant primary tumor of the brain, the glioblastoma is more common for adult population at the localization of lateral ventricles.

The best treatment method of intra-ventricular tumor is surgical resection [1] [3] [4]. Transcortical, interhemispheric trans-callosal or pteryonal (rare) approaches are used for $3^{\text {rd }}$ and lateral ventricles. The transcortical approach was first defined by Dandy in 1992 [5]. Bush introduced the trans-callosal approach in 1944. For lateral ventricle, transcortical approach is more suitable than the trans-callosal approach. It is more commonly preferred due to the wider visual field and easy access to the temporal horn and atrium. Moreover, it enables total extraction of the tumor with less morbidity. Transcallosal approach includes more advantages such as lower rate of postoperative neurological sequel and epilepsy [5]. For our patient, interhemispheric transcallosal approach was preferred for all patients with $3^{\text {rd }}$ ventricle tumor, while transcortical and interhemispheric approaches and stereotactic biopsy were used for 12, 6 and 1 patient(s) with lateral ventricle tumors, respectively. Suboccipital approach is more commonly used for $4^{\text {th }}$ ventricle tumors.

Recently, neuroendoscopic methods gained popularity for approaching ventricular tumors. It is suggested that better vision is provided with less cerebral damage and retraction. The method is challenging for large tumors, although it can be used for all tumors. It is particularly preferred for tumors $<2 \mathrm{~cm}$. The density, consistency and the vascularity of the tumor should be taken into account [5]. It is stated that the method can be used for better visualizing the tumor as a supportive method of the microsurgical method [5]. Endoscopic procedure was not used for our patients. 
Incorrect patient selection, lack of experience and inattention may lead to serious neurological deficits with the trans-callosal approach. The most significant complications of the trans-callosal approach include venous infarction, superior Sagittal sinus thrombosis, disconnection syndrome and temporary memory loss secondary to the thalamus and basal ganglia infarction and and fornix injury [4]. Intraventricular hemorrhage followed by death developed in one of our patients who was operated with this approach.

It was reported that interventions to the lateral ventricle were more commonly associatd with epilepsy (3\% $30 \%)$, visual field defect $(20 \%-60 \%)$ and hemiparesis $(8 \%-30 \%)$. The most common complication for our patients was hydrocephalus followed by meningitis. Although the rate of hydrocephalus and meningitis associated with intra-ventricular hemorrhage was somewhat higher than the rates reported in the literature, on the contrary to the literature, postoperative epilepsy was not observed in the postoperative follow-up of the patients. In comparison with the literature, high rate of hydrocephalus can be explained with the fact that postoperative hemorrhage and meningitis complications were frequent and hydrocephalus developed usually in those patients. It was reported in the literature that the morbidity was 5\% [7] and the mortality was $<10$ percent [6]. For our cases, death following intra-ventricular hematoma was observed in 1 patient (2.5\%) and motor deficit sequel (hemiplegia) was observed in 1 patient (2.5\%).

\section{Conclusion}

The primary treatment method of the ventricular tumors is surgical resection and considering the advantages and disadvantages; transcortical approach stands out for lateral ventricle tumors. The aim should be the total extraction of the tumor with minimum damage. Despite all above mentioned findings, endoscopic approaches gained a recent popularity. It appears more probable that they can be used for assisting the micro-surgical method for small and large tumors.

\section{References}

[1] Abosch, A., McDermott, M.W. and Wilson, C.B. (2000) Lateral Ventricular Tumors. In: Kaye, A.H. and Black, P.M., Eds., Operative Neurosurgery, cilt 1, Churchill Livingstone, London, 800-812.

[2] Amar, A.P., Albuquerque, F.C. and Apuzzo, M.L.J. (2000) Anterior Third Ventricle Lesions (İncluding Colloid Cysts). In: Kaye, A.H. and Black, P.M., Eds., Operative Neurosurgery, cilt 1, Churchill Livingstone, London, 753-768.

[3] Bruce, J.N. (2000) Posterior Third Ventricular Tumors. In: Kaye, A.H., Black, P.M., Eds., Operative Neurosurgery (1st ed.), cilt 1, Churchill Livingstone, London, 769-775.

[4] Kasowski, H. and Piepmeier, J.M. (2001) Transcallosal Approach for Tumors of the Lateral and Third Ventricles. Neurosurg Focus, 10, 1-5. http://dx.doi.org/10.3171/foc.2001.10.6.4

[5] Orakdöğen, M., Karadereler, S., Armağan, S. and Berkman, Z. (2005) İntraventrikuler Tumorler: 22 Olgunun De.erlendirmesi ve Cerrahi Sonucları. Türk Nöroşirürji Dergisi, 15, 17-24.

[6] Strugar, J. and Piepmeier, J. (2000) Approaches to Lateral and Third Ventricular Tumors. In: Schmidek, H.H., Ed., Operative Neurosurgical Techniques, Indications, Methods and Results, cilt 1, dördüncü bask1, WB Saunders Company, 837-851.

[7] Le Gars, D., Lejeune, J.P. and Desenclos, C. (2000) Tumeurs du troisieme ventricule: Revue de la litterature. Neurochirurgie, 46, 296-319.

[8] Majos, C., Coll, S., Aguilera, C., Acebes, J.J. and Pons, L.C. (2000) Intraventricular Mass Lesions of the Brain. European Radiology, 10, 951-961. http://dx.doi.org/10.1007/s003300051044

[9] Morita, A. and Kelly, P.J. (1993) Resection of İntraventricular Tumors via a Computer-Assisted Volumetric Stereotactic Approach. Neurosurgery, 32, 920-927. http://dx.doi.org/10.1227/00006123-199306000-00006

[10] Okechi, H. and Albright, A.L. (2012) Intraventricular Meningioma: Case Report and Literature Review. Pediatric Neurosurgery, 48, 30-34. http://dx.doi.org/10.1159/000341176

[11] Qian, H., Lin, S., Zhang, M. and Cao, Y. (2012) Surgical Management of İntraventricular Central Neurocytoma: 92 Cases. Acta Neurochirurgica, 154, 1951-1960. 